\title{
Las relaciones amorosas en la ficción seriada. Lenguaje audiovisual e imaginarios sociales
}

\section{Love Relationships in Serialised Fiction. Audiovisual Language and}

\section{Social Imaginary}

Sue Aran Rampost. Universitat Ramon Llul

Recibido: 27-XII-2010 - Aceptado: 26-VII-2011

Resumen:

La presente investigación observa entre estudiantes de Master del Institut of Education de la Universidad de Londres los conocimientos que intervienen en su interpretación de la representación de las relaciones amorosas en la ficción seriada televisiva. El marco teórico está en el trabajo del grupo de investigación RETEVIS (Medina et al., 2008; Aran, Medina, Rodrigo, 2010), y se defiende una noción de educación mediática (Buckingham, 2003) que supera la estricta alfabetización en la "gramática" audiovisual. A partir de entrevistas y focus group, se observa la eficacia del conocimiento en lenguaje audiovisual en la elaboración de un discurso analítico y crítico sobre el dispositivo escénico y los contenidos estereotipados, y una demanda de nuevos modelos amorosos en la oferta de ficción.

Palabras clave:

Televisión, educación mediática, amor, imaginarios sociales, interpretación.

Abstract:

This research project studies, among Master's students of the Institute of Education of the University of London, the knowledge that affects their interpretation of the representation of love relationships in televised fiction series. The theoretical framework is the work of the research group RETEVIS (Medina et al., 2008; Aran, Medina, Rodrigo, 2010), and the authors argue for a concept of media education (Buckingham, 2003) which goes beyond mere literacy in audiovisual "grammar". From interviews and focus groups, we observe the effectiveness of the knowledge of media language in the production of analytical and critical discourse about scenic devices and stereotyped contents, and a demand for new models for love in fiction programmes.

Keywords:

Television, Media Literacy, Love, Social Imaginaries, Interpretation. 


\section{Introducción}

La comprensión del impacto social y de las posibilidades de desarrollo que ofrecen los medios de comunicación, requiere previamente -como indica Thompson (1998)- el abandono de una concepción de las relaciones sociales inmóviles. La interacción interpersonal y presencial, el cara a cara, todavía caracteriza la mayoría de las situaciones de la vida cotidiana. Pero esta interacción presencial, ese compartir un lugar común, convive con otras formas de interacción que son las que posibilitan los medios de comunicación. Lo que no tiene sentido es enfrentar estas dos realidades. Thompson (1998: 19) promueve la idea de reinventar la noción de propiedad pública, de manera que refleje las complejas interdependencias del mundo moderno.

Desde nuestra perspectiva -como grupo de investigación RETEVIS (Representaciones Televisivas e Imaginarios Sociales), URL-, y de acuerdo a esa interdependencia entre las relaciones sociales presenciales y las mediadas, nos interesa de manera particular la relación entre realidad social y contenidos mediáticos. Más concretamente, nuestro análisis se dirige al diálogo entre esos contenidos mediáticos y la realidad social para observar la noción de "imaginario público" -parafraseando a Thompson (1998)- o imaginario colectivo.

En recientes investigaciones, y entendiendo el análisis de los relatos televisivos como una de las maneras que tenemos para aproximarnos al discurso social contemporáneo, decidimos centrarnos en las relaciones amorosas. Al plantearnos el abordaje de una dimensión como son los imaginarios sociales sobre el amor dábamos continuidad lógica a nuestra trayectoria individual y conjunta sobre la interpretación de la violencia de ficción por parte de los telespectadores infantiles (Aran, 2008) o los estereotipos de género por parte de los adolescentes y jóvenes (Medina et al., 2007b). Pretendíamos además una aportación singular ante una tradición ya consolidada en nuestro país en lo referido a la investigación de estereotipos en la prensa diaria y la publicidad, pero todavía escasa en la ficción audiovisual, particularmente la televisiva (Galán, 2007).

Nuestro punto de partida sobre las relaciones amorosas es la noción de amor que establece Sternberg (1989). Con dicho marco teórico, desarrollamos diversas investigaciones dirigidas tanto a la representación de las relaciones amorosas en la ficción televisiva seriada (Aran, Medina, Rodrigo, 2010; Medina et al., 2008; Medina, Rodrigo, Aran, 2006), como orientadas a la observación de las percepciones que la población adolescente y joven tiene sobre el amor (Medina, Aran et al., 2007b). Con dicho background, la etapa siguiente ha sido tomar como objeto de estudio la interpretación de los espectadores sobre la representación de las relaciones amorosas ante el mismo corpus audiovisual que analizamos en su momento. La cons- 
trucción de estereotipos de género y las representaciones mediáticas de la violencia simbólica se convierten ahora en un elemento indirecto que abordamos desde el protagonismo del público de los relatos televisivos seriados sobre relaciones amorosas.

También la lógica de los criterios de interdisciplinariedad que configuran el equipo -integrado por profesoras y profesores universitarios procedentes de las teorías de la comunicación, la comunicación audiovisual, la publicidad, la psicología, la filología... entre otras áreas-, nos obligaba a ir más allá de las metodologías habituales en los estudios sobre comunicación, como puede ser el análisis de contenido, para inserir nuestras observaciones en el marco de los Estudios Culturales. Así, RETEVIS enmarca sus líneas de investigación sobre la comunicación social desde dicho marco teórico, los Estudios Culturales, pero desde una perspectiva constructivista e interpretativa.

Inspirándonos en los trabajos de Williams (1975) y Ang (1996), elaboramos una metodología de análisis para la ficción seriada (Medina et al., 2007: 23-24) organizada en tres niveles de análisis:

1. Estructura del Sentimiento Social (ESS), marco general compartido por la mayoría de la sociedad respecto a un tema -en nuestro caso, las construcciones sobre el amor-y que forma parte del sentir dominante;

2. Estructura Narrativa del Sentimiento (ENS), análisis del relato mediático y de cómo aborda el texto la realidad objeto de análisis -en nuestro caso, el sentimiento amoroso-;

3. Estructura del Sentimiento Vivido (ESV), cómo son interpretados los relatos mediáticos por los actores sociales concretos. Cómo reaccionan ante la narrativa televisiva y cómo reinterpretan creativamente de nuevo la Estructura del Sentimiento Social.

Nuestro propósito en el actual desarrollo del modelo, y después de dedicarnos a los dos primeros niveles, ha sido abordar el tercer nivel, la Estructura del Sentimiento (Amoroso) Vivido (ESAV), para analizar cómo se enfrenta el espectador al texto audiovisual. Nuestra hipótesis es que un mayor conocimiento y sensibilidad hacia el lenguaje audiovisual ha de permitir a las personas una comprensión más eficaz de los discursos mediáticos, no sólo como descodificación estricta de una "gramática" como podría ser el caso de la ficción televisiva, sino también de la comprensión de la lógica, los referentes, las ideologías... que confluyen en el espacio comunicativo. De acuerdo con Buckingham (2003: 34), un individuo realmente alfabetizado es capaz no sólo de utilizar el idioma, sino también de comprender cómo funciona. No se trata únicamente de comprender la "gramática" de formas particulares de comunicación; también involucra estar al tanto de los códigos y normas más amplias de los géneros específicos. 
Para ello es necesario analizar tanto el tipo de estrategias que los telespectadores activan en relación al lenguaje y procedimientos de la ficción televisiva, como el reconocimiento por parte de estos mismos telespectadores de los discursos subyacentes. Para efectuar dicho análisis nos hemos situado en el contexto de la educación en medios o educación mediática, partiendo de la propuesta de la Unesco sobre educación en comunicación (2002) y planteándola en términos de educación en comunicación audiovisual (ECA). El sentido de dicha opción se deriva del propio objetivo de la educación mediática, "dotar a las personas de instrumentos para comprender con rigor y de manera crítica los mensajes que consumen, y proporcionarles los recursos necesarios para producir textos o discursos adecuados a las diferentes situaciones de comunicación.” (Fòrum, 2006: 20).

\subsection{Educación mediática e imaginario amoroso en la postmodernidad}

La eficacia de la educación mediática para comprender el lenguaje de las representaciones televisivas sobre el amor, así como el metalenguaje que subyace en ellas, es actualmente más una promesa de futuro que un hecho contrastado. En parte, por los movimientos que se han producido dentro de la propia noción de educación mediática. Como indica Oliva (2006), la educación mediática ha tenido tanto enfoques defensivos (que la entienden como una forma de protección ante los medios) como propuestas vinculadas a la idea de empowerment (entendida como forma de preparación, incluso de participación ciudadana). Pero además, es una modalidad de educación que no es ajena a las llamadas "crisis de representación" o "nueva fase de representación” del paradigma postmoderno. Un paradigma en el que, según Funge (1998), la multiplicidad de lecturas y la ambivalencia de las reacciones ante los medios puede constituirse en norma. En lo relativo a las relaciones amorosas, condicionadas por las cuestiones de género, Funge (1998) señala que en un contexto "postmoderno" sus representaciones contemporáneas no pueden expresarse adecuadamente con conceptos anticuados de "estereotipia”, “imágenes negativas” y "mirada masculina”, a pesar de que -según la propia autora-son precisamente ideas similares a éstas las que continúan circulando en la educación mediática. Por lo que parece puede haber problemas no sólo de naturaleza conceptual sino también ideológicos, y todos ellos dentro del paraguas de la educación mediática.

Sea como sea, cualquier análisis riguroso de la influencia de los medios de comunicación de masas y de sus posibilidades educativas, debe considerar que el cambio no se está produciendo únicamente en la esfera de los nuevos medios, sino también en las nuevas maneras de interactuar que van surgiendo ${ }^{1}$. Por ello,

\footnotetext{
"El argumento no es simplemente que los medios mismos son diferentes, sino también que las formas que los jóvenes tienen para conectarse con ellos -es decir, la manera de interpretarlos, de comprometerse e interesarse por ellos- han cambiado fundamentalmente." (Buckingham, 2003: 160).
} 
la relación entre realidad social y contenidos mediáticos, no sólo requiere en los telespectadores de una cierta práctica en el consumo televisivo, sino también de una cierta activación de la función de referencialidad. Sea a través de la presencia de determinados modelos de ficción de hombre o mujer como por su notoria ausencia -a través de mecanismos de invisibilidad igualmente potentes- el reconocimiento de esos modelos ficcionales o maneras de ser y de querer se ve potenciado a través de los mecanismos de identificación por los/las telespectadores (recurrencia) o, en términos más amplios, por el reconocimiento de ese universo socialmente compartido. Es este un ámbito de estudio todavía reciente y con pocos acuerdos, pero imprescindible en un entorno que pretende dar mayor relevancia tanto al papel de la educación mediática como a las políticas de género.

Por una parte, desde el punto de vista del actual marco político y las obligaciones que genera en la educación mediática, es pertinente recordar la exigencia que supone la Directiva de Servicios de comunicación audiovisual (Directiva 2007/65/CE) del Parlamento Europeo. La nueva Directiva revisa la antigua con la voluntad de modernizar la normativa en relación a la ampliación de contenidos tradicionales que afrontan los reguladores de contenidos con las tendencias actuales en el consumo y en la distribución de contenido audiovisual en la red. La nueva Directiva reconoce que en el entorno de nuevos medios de comunicación, con una tecnología y unos mercados que cambian rápidamente y donde los espectadores se responsabilizan cada vez más de los medios que consumen, la autorregulación y la co-regulación pueden demostrar que son el medio más adecuado y flexible para proporcionar un grado elevado de protección de los consumidores. En este nuevo panorama queda cada vez más clara la limitación de la protección reguladora para otorgar más protagonismo a la responsabilidad del propio usuario. Aquí es donde entra todavía con más fuerza la educación mediática y, de manera particular, la educación en comunicación audiovisual.

Por otra parte, desde el punto de vista de las políticas de género, la evidencia de cambios es forzosamente difícil de establecer, más aún si se pretenden comparaciones entre épocas. Incluso hay voces, como la de Judith Butler (1990) que cuestionan desde la teoría feminista la noción misma de una identidad fija o esencial de género, sosteniendo por el contrario que el género es un tipo de realización o "mascarada". Incluso autoras como Ángela McRobbie (2004) señalan la aparición de otro tipo de personajes femeninos y de nuevas tramas, así como el rechazo por parte de las nuevas generaciones de un cierto feminismo castrador a favor de un post-feminismo más desinhibido y con sentido del humor. En consecuencia, debemos preguntarnos por la eficacia de esa relación entre los contenidos mediáticos y la realidad social.

Los resultados de nuestra investigación nos han de permitir entender hasta qué grado los públicos son unos interpretadores activos de los mensajes que reciben sobre los estereotipos amorosos (roles de género, rela- 
ciones de pareja, violencia simbólica, etc.) a través de la ficción seriada; de dónde proceden los referentes que activan al realizar sus interpretaciones y si tienen que ver con su grado de alfabetización mediática o, mejor aún, de competencia en comunicación audiovisual ${ }^{2}$.

Para observar dicha competencia en comunicación audiovisual hemos respetado cuatro áreas de contenidos, de acuerdo al estudio de D. Buckingham y K. Domaille (2001), sobre la educación en comunicación audiovisual en diferentes países del mundo:

a) Lenguaje: aspectos relacionados con la estética, la narrativa, los géneros y sus convenciones, la puesta en escena propia de cada medio.

b) Representación: valores e ideología que transmiten los mensajes de los medios, los estereotipos, los puntos de vista, la relación entre realismo y construcción de la representación.

c) Producción: estudio del contexto de producción (industrias, organizaciones, instituciones, etc.), y de los aspectos económicos, las prácticas profesionales, el concepto de autoría, etc.

d) Audiencias: desde la reflexión sobre el propio uso que se hace de los medios al estudio del papel que desempeñan en la construcción de la identidad, la respuesta a los medios de diferentes tipos de audiencias, cómo la audiencia es construida o la influencia de los medios en la vida social y el sistema político.

A efectos de este artículo, nos centraremos en el área de contenidos de lenguaje, reconociendo su interrelación con las otras áreas. Así, la investigación empírica que presentamos observa durante los meses de Enero a Mayo del 2010 entre estudiantes del MA Media, Cultura and Communication del IOE (Institut of Education) de la Universidad de Londres en colaboración con el CSCYM (Centre for the Study of Children, Youth and Media, dirigido por el profesor David Buckingham), la incidencia que puede tener su conocimiento y sensibilidad del lenguaje audiovisual a la hora de ser ellos y ellas mismas sujetos activos en la interpretación de la representación de las relaciones amorosas en la ficción seriada televisiva.

La decisión de centrarnos en un público joven y conocedor del sentido de la educación mediática viene dada por dos criterios: por un lado, aproximarnos a la cultura juvenil contemporánea desde los usos que hacen los jóvenes de los medios para definir y construir tanto sus identidades de género como la propia conceptualización de las relaciones amorosas; por otro -y sin saber todavía si esos usos de los medios son significativamente diferentes de las formas utilizadas anteriormente-, observar si un grado de conocimiento

2 Para ampliar la noción de competencia en educación audiovisual y sus indicadores ver Ferrés (2006). 
en lenguaje audiovisual intensifica las habilidades para el análisis de la relación entre los cambios sociales -en particular, las relaciones entre hombres y mujeres en un contexto de creciente igualdad de los génerosy sus representaciones mediáticas.

Reconociendo las dificultades de las implicaciones de este tipo de fenómenos en el terreno de la "política de identidad" y en la educación, y con el objetivo de analizar la interpretación de los espectadores sobre la representación de las relaciones amorosas presentes en la ficción seriada, hemos organizado la investigación que aquí resumimos, de acuerdo a los objetivos que se exponen a continuación.

\section{Objetivos de la investigación}

La investigación que presentamos, en el marco de un estudio más amplio dedicado a los procesos interpretativos de los jóvenes telespectadores ante la representación de las relaciones amorosas en la ficción seriada, persigue aquí el objetivo siguiente:

Analizar la incidencia que tiene en jóvenes universitarios su conocimiento del área de contenido del lenguaje audiovisual en la comprensión e interpretación de las relaciones amorosas cuando se exponen a su representación en la ficción televisiva seriada.

Este objetivo general se concreta en los siguientes objetivos específicos:

1. Discernir si los sujetos activan competencias mediáticas a partir de su conocimiento de la dimensión de lenguaje audiovisual, en relación a la representación del amor en la ficción seriada.

2. Identificar en el testimonio de los sujetos si establecen distinciones entre la concepción personal sobre el amor y su percepción de la representación mediática.

\section{Metodología}

A partir de la perspectiva constructivista e interpretativa, el planteamiento del análisis del discurso de los participantes en la investigación no lo entendemos como una manera transparente de representar la realidad, sino como una construcción de esa realidad o experiencia que le da significación. Por ello, los instrumentos utilizados para evaluar la presencia y uso de conocimientos sobre lenguaje y análisis crítico del discurso audiovisual de la ficción seriada sobre las relaciones amorosas se complementan mutuamente para abordar esa significación. A partir de la selección del corpus audiovisual y de los participantes, el dispositivo se organiza en una serie de entrevistas semi-estructuradas y en un focus group. 


\subsection{Corpus audiovisual}

Tres secuencias procedentes de diferentes series de ficción de la programación televisiva ("Desperate Housewifes” -en España, "Mujeres desesperadas”-; “Brothers \& Sisters”-“Cinco hermanos”- y “Porca Misèria”).

La muestra analizada comprende la primera temporada de las tres series.

Desperate Housewives ("DH”) es una serie estadounidense que emite la cadena de televisión ABC desde el año 2004. En la sinopsis de la primera temporada se nos habla de cómo en la comunidad de Wisteria Lane viven un grupo de cuatro mujeres y de cómo accederemos a través de sus puntos de vista a las vivencias de la gestión amorosa y familiar.

Brothers \& Sisters ("B\&S") es otra serie estadounidense que inició sus emisiones en el año 2006. La serie ha sido emitida por ABC y la Fox. De acuerdo con las descripciones promocionales de la serie, la familia protagonista, los Walker, no son una familia cualquiera. Liderada por Nora, la matriarca, el clan formado por los cinco hijos de ésta, sus parejas, su hermano Saúl y otros personajes colaterales pretende ser una radiografía de la sociedad contemporánea, en la que tienen cabida desde dilemas morales hasta la guerra de Irak.

"Porca Misèria” (“PM”) es una serie de TV3 producida por Arriska Films y dirigida por Joel Joan. Se comenzó a emitir en noviembre del 20043. En un tono de comedia en la primera entrega, "Porca Misèria" gira alrededor de las peripecias de una pareja protagonista: Pere (guionista de televisión) y Laia (bióloga dedicada a la investigación), y sus amigos. Entre todos escenificarán cuatro relaciones amorosas (la de Pere y Laia, la de Roger -hermano de Pere- y Sònia, la de Natàlia y Jordi, y la de Alex con diferentes mujeres). Esta multiplicidad de relaciones amorosas desarrolladas en el guión es posible, especialmente, porque la serie se aleja del terreno conocido de 'la guerra de sexos', mostrando cuatro posibles tipos de relación amorosa más actualizadas y complejas, como corresponde a los entresijos de la sociedad contemporánea (Medina et al., 2007).

Criterios de selección del corpus:

Temático: son series de ficción televisiva actuales en entornos urbanos que nos presentan protagonistas femeninas que invitan a la reflexión sobre la mujer y, en general, sobre las relaciones amorosas, sin centrar la trama en el ámbito profesional.

Narrativo: la estructura narrativa de las series escogidas permite comparar dos tipos diferentes de organización de la trama - plural en los diversos núcleos interconectados en Porca Misèria (parejas

Desde entonces la serie ha recibido el Premio Ondas (2006); Premis GAC (2005); Premis Barcelona de Cine (2005); y quedó finalista en el Festival de Televisión de Montecarlo (2005). 
como núcleos) y Desperate Housewives (núcleos familiares); coral en Brothers \& Sisters desde un núcleo matriz -el grupo familiar y la madre, respectivamente- que conecta con otros núcleos familiares dependientes.

Simbólico: Tanto desde el punto de vista de la procedencia de su producción, específicamente las estadounidenses, como de la acogida y/o distribución que han tenido, son series emblemáticas de la potencia intensiva (y extensiva en el caso de las dos series estadounidenses) de la industria audiovisual y de los discursos dominantes que, mayoritariamente desde los EEUU, marcan tendencias. La buena acogida de las series por parte de los telespectadores e internautas corrobora la amplia difusión e implantación de dicho referente, ya sea a escala nacional como internacional.

La selección específica de las secuencias o clips se ha ajustado según criterios de:

- $\quad$ Representatividad de modelos amorosos, de acuerdo al modelo de Sternberg: los dos primeros ejemplos ("Desperate housewifes" y "Brothers \& Sisters") de intimidad amorosa- "DH” con signos claros de pasión (amor romántico); “B\&S” con signos de compromiso (amor compañero); el tercer ejemplo (“Porca Misèria”) muestra un amor consumado -signos de intimidad y compromiso, aunque la pasión no se explicita- en una pareja joven y, a su vez, estable. Tipos de pareja: madura heterosexual; joven homosexual; joven heterosexual, respectivamente.

- $\quad$ Presencia de recursos del lenguaje audiovisual diversos: protagonismo de los diálogos respecto a la acción; presencia de música; interpretaciones y puesta en escena propios de la narrativa cinematográfica clásica (clips 1 y 2) versus un estilo y uso de la cámara más pretendidamente espontáneo y "transparente" ${ }^{4}$ (clip 3).

- $\quad$ Inteligibilidad (sin ser escenas autoconclusivas, ofrecen elementos mínimos para su comprensión sin contexto)

- $\quad$ Duración similar y brevedad (ninguna de ellas dura más de tres minutos).

De acuerdo a dichos criterios se han escogido: de 'Desperate housewifes' el capítulo 4, "Imágenes idílicas" -escena del diálogo entre Susan y Mike sobre la cena a la que han asistido y alusión a un incidente sucedido a Susan por la mañana- (minutos 00:31:23-00:32:38); de "Brothers \& Sisters" el capítulo 3, "Relaciones de estado" -escena del diálogo entre Kevin Walker y Scotty en relación al patriarca Walker- (minutos

En relación a las características de estos dos estilos o concepciones, remitimos a la emblemática noción de cine de la "transparencia" de Bazin (1990), así como a las definiciones del sistema narrativo clásico de Bordwell (1996), entre otros autores. 
00:28:15-00:28:56); de “Porca Misèria" el capítulo 6, "Errare humanum est”, -escena del diálogo entre Pere y Laia sobre el descubrimiento científico de ella y los giros del guión que él escribe- (minutos 00:32:48:1300:35:10:22).

\subsection{Participantes}

- $\quad$ Un grupo (13) de estudiantes del MA Media, Culture and Communication del IOE (Universidad de Londres).

- $\quad$ Un grupo (a, 11 sujetos) procedente de la asignatura "Research in Media, Cultural Studies and Education” (Profesoras Liesbeth De Block y Rebekah Willet) sobre investigación teórica y metodológica en comunicación; un segundo grupo (b, 7 sujetos) procedente de la asignatura "Youth Culture, Media and Education" (Profesor David Buckingham) sobre jóvenes y cultura mediática. Algunos de los sujetos (4) participan en ambas asignaturas.

Criterios de selección de los participantes:

- $\quad$ Estudiantes de Tercer Ciclo de estudios especializados en cultura y educación mediática.

- $\quad$ Edades comprendidas entre los 24 y los 30 años.

- $\quad$ Diversidad de etnias y nacionalidades de origen.

- $\quad$ Proporcionalidad entre géneros.

\subsection{Etapas y procedimiento}

El procedimiento sigue la metodología de análisis para la ficción seriada (Medina et al., 2007) explicada anteriormente y de acuerdo a sus tres niveles de análisis:

- $\quad$ Estructura Narrativa del Sentimiento (ENS), análisis del relato mediático y de cómo aborda el texto la realidad objeto de análisis -en nuestro caso, el sentimiento amoroso-.

- Selección y análisis de contenido del corpus audiovisual (por parte de los investigadores).

- Selección de los participantes (grupos a y b)

- $\quad$ Estructura del Sentimiento Vivido (ESV), cómo son interpretados los relatos mediáticos por los actores sociales concretos. Cómo reaccionan ante la narrativa televisiva y cómo reinterpretan creativamente de nuevo la Estructura del Sentimiento Social. 
- Entrevista semiestructurada (individual, grupo a, 10 participantes) después del visionado de las tres secuencias sobre la representación de ficción de los modelos amorosos, y sobre la función e interpretación de los códigos expresivos y recursos narrativos y estéticos presentes en los tres ejemplos audiovisuales. La entrevista contempla un total de diez preguntas, de las cuales analizaremos dos referidas a los aspectos formales del lenguaje audiovisual y dos sobre la valoración de los sujetos sobre las tres secuencias.

- Grupo de discusión (grupo b, 7 participantes) -después del visionado-sobre impresiones y sobre la representación ficcional de los modelos amorosos y sobre la función e interpretación de los códigos expresivos, recursos estéticos e implicaciones ideológicas presentes en los tres ejemplos audiovisuales.

Análisis e interpretación de los datos de carácter cuantitativo y cualitativo (programa N’Vivo 8.0): Análisis de contenido y del discurso de las entrevistas entre estudiantes universitarios del IOE de la University of London. Análisis del discurso del resultado del grupo de discusión (focus group). Contraste de los resultados con otros dos investigadores.

En esta etapa, seguimos la propuesta de análisis del discurso de Buckingham (2005), que organiza la comunicación de significados a partir del lenguaje audiovisual teniendo en cuenta los objetivos planteados. Se establecieron tres dimensiones de análisis del discurso en función de los aspectos contemplados en los objetivos. 
Tabla I. Procedimiento de análisis del discurso

\begin{tabular}{|c|c|c|}
\hline Objetivo & Pregunta & Dimensión de análisis \\
\hline $\begin{array}{l}\text { 1. Interpretación de las relaciones } \\
\text { amorosas en la ficción seriada (in- } \\
\text { cidencia de la dimensión del } \\
\text { lenguaje audiovisual). }\end{array}$ & $\begin{array}{l}\text { Identifica tres recursos expresivos } \\
\text { del lenguaje audiovisual significa- } \\
\text { tivos en cada secuencia. } \\
\text { ¿Qué es lo que más/ menos te ha } \\
\text { gustado? }\end{array}$ & $\begin{array}{l}\text { a. Distinciones en la dimensión de } \\
\text { lenguaje audiovisual sobre la re- } \\
\text { presentación del amor. } \\
\text { b. Consideraciones de placer o } \\
\text { disgusto sobre la representación } \\
\text { de las relaciones amorosas } \\
\text { c. La noción de amor y tipos de } \\
\text { relaciones amorosas en las imá- } \\
\text { genes visionadas. }\end{array}$ \\
\hline $\begin{array}{l}\text { 2. Interpretación de las relaciones } \\
\text { amorosas en la ficción seriada } \\
\text { (distinciones entre la concepción } \\
\text { personal sobre el amor y su per- } \\
\text { cepción de la representación } \\
\text { mediática). }\end{array}$ & $\begin{array}{l}\text { ¿Cómo se representan las relacio- } \\
\text { nes amorosas? ¿Por qué? }\end{array}$ & $\begin{array}{l}\text { a. Intervención de indicadores de } \\
\text { lenguaje en las consideraciones } \\
\text { sobre la representación del amor. } \\
\text { b. Consideraciones (nivel de } \\
\text { aceptación) de la representación } \\
\text { ficcional del amor. } \\
\text { c. La noción de amor y tipos de } \\
\text { relaciones amorosas en las imá- } \\
\text { genes visionadas. }\end{array}$ \\
\hline
\end{tabular}

La información fue analizada siguiendo parcialmente los principios de la Lineation Theory y las etapas sugeridas por Taylor y Bogdan (1996). Así, la primera autora y una investigadora conocedora del proyecto analizaron conjuntamente un 10 \% de la información y establecieron las categorías de análisis. Dos profesores investigadores del IOE y del CSCYM (Centre for the Study of Children, Youth and Media) de la University of London analizaron el resto de los datos. El acuerdo fue del $80 \%$. Los pocos casos en los que hubo desacuerdo se discutieron hasta llegar al consenso. Este procedimiento nos permitió garantizar la triangulación de la interpretación (King, Keohane y Verba, 1994).

- Informe de resultados. Propuestas de actuación. 


\section{Resultados}

\subsection{Las entrevistas}

Después del visionado de las tres secuencias, de un total de 10 preguntas sobre la representación de ficción de modelos amorosos, presentamos aquí los resultados de dos cuestiones específicas: los recursos de lenguaje audiovisual que más significativos les resultan para su comprensión, y aquello que gusta y lo que disgusta de las secuencias visionadas. Recordemos que en el contexto de este artículo, la finalidad de dicha selección es a tres niveles: identificar la intervención de indicadores de lenguaje audiovisual y criterios estéticos en las argumentaciones de los participantes; conocer la incidencia de dichos indicadores en las valoraciones concretas de los participantes sobre las secuencias y sobre los tipos de relaciones amorosas; inferir la noción de amor y de tipos de relaciones amorosas que los participantes reconocen en la representación de ficción.

a. Recursos expresivos de lenguaje audiovisual más destacados por los sujetos (S) como ayuda en la comprensión de cada secuencia

Preguntados los sujetos sobre los tres aspectos de lenguaje audiovisual ("recursos expresivos") que mejor caracterizan a cada secuencia, aparece una variedad de nociones, no específicamente relativas al estilo/estética de la historia representada, pero sí reveladoras de la función y significación que le atribuyen los sujetos. Por ello, las hemos agrupado en conceptos en función de esa significación:

A. Categorías estéticas (“colourful”, “dynamism”, "darkness”, “dark yellow”, “casual dress”; "slow music”; "soft instruments"...)

B. Categorías sobre recursos técnico-expresivos ("steady camera", "closeness -close shot"...)

C. Categorías de género y formato audiovisual (“drama”, "romance”, “comedy”, “soap”, “deliberative”...)

D. Categorías ideológicas ("midle class", "wealthy family”, "stereotypical”, "typically attractive maleness"...)

E. Criterios (o consideraciones) de gusto ("good music”, "normal”, "atypical”,"sincere”...)

Los comentarios referidos a las dos primeras secuencias (“DH” y "B\&S”) presentan una mayor atribución a las categorías de tipo estético y a criterios de gusto con alguna implicación ideológica, respecto a las del tercer ejemplo ("PM"), de tipo estético y técnico-expresivo. En general, este tercer ejemplo se entiende como más “oscuro”, más “dark yellow”, más informacional y próximo (entre realista y sórdido) a los sujetos que los 
dos anteriores, donde destaca el primero ("DH”) como objeto de comentarios críticos a la representación estereotípica de personajes y géneros ("typically attractive maleness”), aún sin ser el objeto de la pregunta.

A partir de sus comentarios, hemos elaborado una tabla en la que organizamos exclusivamente aquellos elementos que pueden considerarse específicamente recursos de lenguaje audiovisual. Reconociendo la simplificación que supone, hemos diferenciado cuatro dimensiones: texto/guión; música y sonido; interpretación actoral y puesta en escena.

Tabla II. Recursos audiovisuales destacados por los sujetos (S)

\begin{tabular}{|c|c|c|c|c|c|c|c|c|}
\hline Comentarios: & $\begin{array}{l}\text { Texto/Guión } \\
\text { (dinamismo en diálo- } \\
\text { gos, registro de habla, } \\
\text { terminología) }\end{array}$ & & $\begin{array}{l}\text { Música, } \\
\text { sonido }\end{array}$ & & \begin{tabular}{|l} 
Interpretación \\
actoral (expresio- \\
nes faciales, \\
actitud corporal, \\
movimientos de \\
aproximación)
\end{tabular} & & $\begin{array}{l}\text { Puesta en } \\
\text { escena (am- } \\
\text { bientación de } \\
\text { los espacios, } \\
\text { vestuario, ilu- } \\
\text { minación) }\end{array}$ & \\
\hline Clip 1 (33) & $\mathrm{S} 1(2), \mathrm{S} 4, \mathrm{~S} 10$ & 4 & $\begin{array}{l}\text { S2, S3, S6, S7 } \\
(2), S 9, S 10\end{array}$ & 7 & $\begin{array}{l}\text { S2 (3), S3, S4, S5, } \\
\text { S9 (3) }\end{array}$ & 9 & $\begin{array}{l}\text { S3 (2), S4, S5 } \\
\text { (2), S6 (2), S7, } \\
\text { S8 (3), S9, S10 }\end{array}$ & 13 \\
\hline Clip 2 (24) & S4, S9, S10 & 3 & S1, S7, S9 & 3 & $\begin{array}{l}\text { S2, S3, S4 (2), S5, } \\
\text { S10 }\end{array}$ & 6 & \begin{tabular}{|l} 
S3 (2), S5 (2), S6 \\
$(2), S 7$, S8 (2), \\
S9 (2), S10
\end{tabular} & 12 \\
\hline Clip 3 (15) & S4, S10 & 2 & & 0 & $\begin{array}{l}\text { S2, S3, S4 (2), S5 } \\
(2), S 6, S 10\end{array}$ & 8 & S2, S3, S5, S8, S9 & 5 \\
\hline TOTAL & & 7 & & 10 & & 23 & & 30 \\
\hline
\end{tabular}

Los resultados obtenidos en el análisis de los recursos audiovisuales más destacados por los participantes, tomados en su conjunto, muestran una mayor presencia de dos de las cuatro dimensiones consideradas: interpretación actoral (23) y puesta en escena (30). En la puesta en escena se han incluido las menciones puntuales (3) a elementos técnico-expresivos (movimientos y altura de cámara; tipo de plano) pero aún sin ellas seguiría siendo la categoría más significativa. En último lugar han quedado los comentarios referidos a la información que aportan los diálogos; sin embargo, en un análisis más detallado, debemos señalar que si atribuyéramos al guión los comentarios sobre la actuación actoral en tanto provienen de acotaciones in- 
terpretativas, el incremento sería significativo (30). Aún así, hay que destacar que se igualaría en importancia a la atribuida a la puesta en escena.

Los resultados obtenidos por secuencias muestran cómo las dos primeros clips suscitan la mayoría de comentarios, donde el clip 1 supera en más del doble las menciones al clip 3. Se observa una relación directa entre el incremento de comentarios por secuencia y el incremento de consideraciones de orden estético y de gusto con alguna implicación ideológica.

b. Valoración de los Sujetos (S) en relación a cada secuencia

Los resultados obtenidos se muestran respetando las cuatro dimensiones anteriores, y en la tabla III se muestran indicando gráficamente si la valoración es positiva (+) o negativa (-). 
Tabla III. Valoración de los Sujetos (S) en relación a cada secuencia

\begin{tabular}{|c|c|c|c|c|c|c|}
\hline & & Texto/Guión & $\begin{array}{l}\text { Música, } \\
\text { sonido }\end{array}$ & $\begin{array}{l}\text { Interpretación } \\
\text { actoral }\end{array}$ & Puesta en escena & TOTAL \\
\hline \multirow[t]{2}{*}{ Clip 1} & + & $\begin{array}{l}\text { S1, S9 (cotidianeidad, positivismo), } \\
\text { S6 (glamour, escapismo) S3 (humor) } \\
\text { S4, S8, S10 (el coqueteo) S7 (cierto } \\
\text { suspense) }\end{array}$ & $\begin{array}{l}\text { S5 (música en } \\
\text { background) }\end{array}$ & $\begin{array}{l}\text { S2 (expresión pers. } \\
\text { Femenino y mascu- } \\
\text { linidad gentil) }\end{array}$ & S8 & 11 \\
\hline & - & $\begin{array}{l}\text { S2 (inacabado), S3, S5, S6 (previsibi- } \\
\text { lidad, en diálogo y reacciones), S4, } \\
\text { S7, S8 (esquematismo roles género, } \\
\text { part fem: masc fuerte vs fem débil) }\end{array}$ & & $\begin{array}{l}\text { S1, S3 (expresión y } \\
\text { cambio pers. Feme- } \\
\text { nino) }\end{array}$ & $\begin{array}{l}\text { S4 (iluminación } \\
\text { encuadre perso- } \\
\text { naje upstairs) }\end{array}$ & 10 \\
\hline \multirow[t]{2}{*}{ Clip 2} & + & $\begin{array}{l}\text { S3, S9 (no esterotipificación), S6 } \\
\text { (universalidad de la cuestión), S10 } \\
\text { (flirteo) }\end{array}$ & S1, S9 (música) & $\begin{array}{l}\text { S4, S8 (intención de } \\
\text { victoria del perso- } \\
\text { naje optimista: } \\
\text { actuación, upstairs) }\end{array}$ & $\begin{array}{l}\text { S2 (fotografías } \\
\text { pared), S10 (color, } \\
\text { tonalidad, set es- } \\
\text { calera) }\end{array}$ & 10 \\
\hline & - & $\begin{array}{l}\text { S1 (inacabado) S2, S3 (indefinición } \\
\text { sexual personajes), S4 (no acepta- } \\
\text { ción homosex. Personaje) S5, S6, S7, } \\
\text { S8 (respuestas demasiado guioniza- } \\
\text { das o tipificadas) }\end{array}$ & & & & 8 \\
\hline \multirow[t]{2}{*}{ Clip 3} & + & $\begin{array}{l}\text { S1, S3, S6, S9 (naturalidad, realismo, } \\
\text { cotidianeidad, proximidad entre per- } \\
\text { sonajes) S4 (identificación) }\end{array}$ & & & & 5 \\
\hline & - & $\begin{array}{l}\text { S1 (indefinición relación) S2 (irrele- } \\
\text { vancia conversación) S6, S8, S10 } \\
\text { (interrupciones en conversación, ra- } \\
\text { pidez y densidad diálogos), S3, S4, } \\
\text { S7, S8 (desatención del pers. Masc.) }\end{array}$ & & & $\begin{array}{l}\text { S5 (colores y mo- } \\
\text { vimientos de } \\
\text { cámara) S10 } \\
\text { (densidad visual) }\end{array}$ & 11 \\
\hline Total & & 41 & 3 & 5 & 6 & \\
\hline
\end{tabular}


En el análisis de los resultados obtenidos conviene señalar que el total de los comentarios efectuados, aun siendo significativo, requiere del detalle de los motivos de cada valoración positiva y/o negativa. El dato que llama más la atención es que prácticamente no hay referencias a la interpretación ni a la puesta en escena, y contrariamente a las respuestas sobre los tres recursos más relevantes, aquí destacan los comentarios valorativos sobre aspectos del guión (41).

Nuevamente se observa que la secuencia 1 duplica el número de comentarios de la secuencia 3, pero sólo en los de carácter positivo. Entre estos, destacan claramente aquellos aspectos del guión que confieren naturalidad y proximidad a las situaciones y una cierta empatía -si no identificación- con los personajes y la trama amorosa. Como datos paradójicos, en una misma secuencia (clip 2) se valora tanto la representación no estereotipada de los roles de pareja como se rechaza lo contrario. Lo mismo ocurre en el clip 3, pero en relación a la apreciación de proximidad-desatención entre los personajes. En sólo un caso se valora el efecto glamouroso.

Entre los motivos negativos, destacan las consideraciones de esquematismo y previsibilidad de la trama, personajes y diálogos, y en menor medida la tipificación en aspectos de la puesta en escena (S2) o interpretación (S4, S8). Se mencionan críticamente aspectos referidos a la fragmentación de la escena o a la propia noción de serialidad. El clip 3 es el que reúne más comentarios (5) molestos con la rapidez y densidad, tanto de los diálogos como de los movimientos de cámara rápidos, convenciones propias del realismo que tan positivamente se le ha valorado (5).

La noción de amor y tipos de relaciones amorosas en las imágenes visionadas.

Amor romántico

- $\quad$ Primera secuencia. Todos los participantes $(n=10)$ han reconocido en el ejemplo la modalidad de amor romántico, de acuerdo al modelo de Sternberg (1989). Las características más mencionadas son "atracción”, “coqueteo" (o flirteo) y "romance”, a partir de comentarios sobre el guión y puesta en escena -en menor medida, sobre el casting y la música-, asociados ocasionalmente con "excitación" y "enamoramiento" a partir de elementos de la interpretación actoral. Aparecen dos menciones a una relación de dominio-sumisión en el guión y en la puesta en escena, una de ellas con la asociación a los "códigos (amorosos) de clase media” (S7).

Amor compañero

- Segunda secuencia. En este ejemplo, la mayoría de los participantes (8/10) han reconocido la relación amorosa en su fase incipiente. Dos sujetos se refieren a una relación de amistad (S3, S9). 
El resto de sujetos han mencionado características del amor romántico, también mayoritariamente a partir de comentarios sobre el guión y puesta en escena -en menor medida, sobre la música-. A las referencias de romance y juego (S1, S3, S10) se añade un elemento de dominio o liderazgo en clave moral a partir del diálogo y la puesta en escena ( S2, S4, S7, S8) que señala una relación más compleja que en la primera secuencia. Únicamente 4 sujetos/ 8 han explicitado que se trata de una relación homosexual (S4, S5, S8, S10).

Amor consolidado, consumado

- Tercera secuencia. Más de la mitad de los participantes (S1, S2, S3, S5, S6, S7, S8) no reconocen que haya una relación amorosa consolidada y se inclinan a partir de su interpretación del guión y puesta en escena por atribuir a los protagonistas una relación amistosa, de carácter profesional o incluso fraternal. No se menciona la noción de romance. Sólo dos sujetos reconocen una relación consolidada basada en los signos de "confianza" y "complicidad” de la comunicación verbal y no verbal -guión e interpretación- de la pareja (S4, S5), pero la mayoría destaca a partir de esos mismos elementos las características de "incomunicación” (S1, S10) “desatención” (S3) o competividad (S2, S6, S9).

\subsection{El focus group}

I. Consideraciones sobre la representación ficcional del amor: intervención de aspectos estéticos y formales propios del lenguaje audiovisual

1. Los participantes incorporan en sus comentarios sobre la representación ficcional del amor múltiples alusiones a aspectos estéticos y formales del lenguaje audiovisual, así como a las convenciones de género audiovisual.

a. Estructura narrativa y guión

b. La mayoría de los participantes (5/7) consideran que la estructura narrativa del discurso se enmarca en las convenciones de los guiones "mainstream" (S6), la corriente dominante (presentación, "gancho" (sic) e interrogante sobre la resolución de la situación apuntada) en una valoración que va de máxima convencionalidad (secuencia 1, "Desperate housewifes") a menor (secuencia 2, "Brothers \& Sisters"), e incluso se sugiere como estructura "alternativa" o novedosa el tercer clip (secuencia 3, "Porca Misèria”). La construcción de los personajes es el aspecto que predomina en los comentarios. Aquí los participantes dirigen mayoritariamente su crítica hacia la primera 
secuencia, y en concreto a la atribución de valores convencionales a la mujer ("comportamiento adolescente", "ñoño" ante las "galanterías" del personaje masculino (S2- She turned into a little girl, giggling, but she wasn't in the first half of the scene) y, en menor medida, al hombre.

c. Esta misma crítica se traslada en menor grado a la representación en la segunda secuencia de los supuestos roles en la pareja homosexual, con un miembro "sensible y afeminado en sus gestos” y otro más reprimido y "masculino" en su comportamiento. Aparece algún comentario sobre la menor representación en la ficción de las parejas homosexuales femeninas.

d. La consideración sobre los personajes de la tercera secuencia es menos consensuada y los participantes no han efectuado apreciaciones negativas sobre el papel atribuido a cada uno de los dos personajes (hombre y mujer).

2. Banda sonora (música y sonido)

a. Los comentarios sobre la banda sonora se dirigen a señalar su función expresiva más allá de la referencial, como anticipadores de una situación emocional o como indicadores de género audiovisual, dentro de las convenciones habituales y favoreciendo una interpretación unívoca del espectador.

S3: the music is upbeat...is quite light. It's got this kind of (imitates music)... very light. very cheeky feeling to it...it has a slight comedic tone but not overly...you're not gonna laugh out loud...

3. Interpretación actoral

a. Los comentarios se dirigen mayoritariamente al casting (selección de actores diferenciada entre los dos primeros ejemplos (S6- "made in USA”) y el tercero, considerado menos glamoroso y más "realista”. También hay referencias a la interpretación de acuerdo a las pautas de guión (construcción de personajes), un elemento que se apuntaba en los resultados de las entrevistas.

4. Puesta en escena

a. Destaca la eficacia narrativa e ideológica que los sujetos atribuyen a aspectos concretos de la puesta en escena (clip 1: el porche de la casa como marco escenográfico, la disposición del hombre abajo y la mujer en lo alto de las escaleras; clip 2: la escalera también connota consideraciones de superioridad moral...), de vestuario ( $1^{\circ}$ clip: la rebeca que viste modosamente la protagonista) y de orden técnico-expresivo, en menor presencia (clip 3: cámara en movimiento y encuadres más cerrados). 
Como contrapunto a las críticas mayoritarias al estilo "made in Hollywood", los participantes señalan series en la línea de "Six feet under" ("A dos metros bajo tierra”) (EEUU), "Shameless" (England), o incluso "House" (EEUU). En este mismo contexto estilístico se pueden entender los comentarios sobre la secuencia de "Porca Miseria", de la que agradecen su formato "realista", aunque entre algunos participantes el diálogo entre la pareja les resulta tenso y/o alejado de las convenciones de una relación amorosa -como es el caso ${ }^{5}-$.

II. Consideraciones (nivel de aceptación) de la representación ficcional del amor.

1. En relación al papel otorgado en la relación amorosa a los personajes, queda patente la crítica a su encorsetamiento y a los estereotipos de género. Dicha crítica señala aspectos narrativos y expresivos para fundamentar argumentos ideológicos. La mayoría de los participantes (5/7) reclaman unos planteamientos más contemporáneos sobre el relato de la intimidad amorosa y en esa reclamación están correctamente fundamentadas consideraciones de lenguaje y estilo audiovisual.

3- I don't particularly want to watch characters that are really really mainstream kind of ...stereotypical straight couples... that has no relevance to my life...so I much rather watch characters who are more the gender-bending kind of end of the spectrum. I'm just thinking on the other end of the spectrum you've got things like soap opera where you have a slowed character development and you've got that very naturalistic style of shooting, particularly with British soap operas, not the American stuff, but the British soap opera which is very naturalistic in the way the characters develop and the way it's set, and the characters' story lines. Again, relationships develop at a much slower pace, more natural pace, if something sexual might happen it's not because of some (not clear) that comes off the cuff.

III. Tipos de relaciones amorosas en la ficción seriada visionada

1. Los participantes identifican adecuadamente las dos relaciones en fase de intimidad incipiente (heterosexual y homosexual, clips 1 y 2 respectivamente) y una tercera no amorosa (dificultad de deducir en ella un vínculo amoroso) o bien en una etapa de consolidación. En la pareja del clip 1, señalan críticamente la explicitación casi caricaturesca de la fase de "flirteo", entre adultos pero con claras connotaciones adolescentes, sobre todo por parte del personaje femenino.

No descartamos una cierta desviación de la incidencia que este clip tenga respecto a los dos precedentes, al ser el único que se presenta en versión original (catalán) subtitulado en inglés. 


\section{Discusión y conclusiones}

Los resultados obtenidos permiten, a grandes rasgos, confirmar nuestra hipótesis aunque del análisis detallado de los mismos se desprende la necesidad de conectar el conocimiento del lenguaje audiovisual con el resto de dimensiones que exige la competencia en comunicación audiovisual, de acuerdo a una noción compleja de la educación mediática.

La influencia de la educación mediática en una mayor capacitación crítica y creativa de los espectadores parece un factor innegable, pero a menudo se presenta como una incidencia simple y directa. Recordemos que nuestra hipótesis es que un nivel suficiente de educación mediática ha de permitir a las personas una comprensión más eficaz de los discursos mediáticos, no sólo como descodificación estricta del lenguaje audiovisual en el caso de la televisión sino también de la comprensión de los factores contextuales que confluyen en el espacio comunicativo. Sin embargo, la educación mediática no es una panacea, ni debe ser depositaria en exclusiva de la comprensión del impacto social y de las posibilidades de desarrollo que ofrecen los medios de comunicación. Pero su función es esencial para ambos aspectos. En definitiva, pensamos que es necesario diseñar investigaciones que superen la "cultura de test6" y que colaboren en un concepto de educación mediática complejo, basado en competencias y prácticas evaluativas, y conectado con la realidad socioeconómica desde una dimensión dinámica.

En la investigación presentada, hemos tratado de impulsar ese concepto de educación mediática focalizándolo en un ámbito que afecta de manera particular a las nuevas generaciones, históricamente depositarias de una relación entre géneros más igualitaria. A partir del análisis del conocimiento del lenguaje audiovisual que tiene un grupo de jóvenes universitarios especializados en educación mediática, nos hemos propuesto observar la incidencia que dicho conocimiento puede tener en la comprensión e interpretación de las relaciones amorosas en la ficción televisiva seriada. Este objetivo general ha quedado demostrado a partir de los objetivos específicos planteados.

En primer lugar, cabe remarcar cómo los sujetos activan competencias mediáticas a partir de su conocimiento de la dimensión de lenguaje audiovisual, en relación a la representación del amor en la ficción seriada. En especial, destacamos:

Conocimiento aplicado bastante exhaustivo de algunos criterios narrativos y de los recursos expresivos del lenguaje audiovisual, en particular de las características de la puesta en escena y, en menor medida, de los recursos técnicos del lenguaje audiovisual.

6 Utilizamos aquí un concepto que Monereo, Castelló et al. (2009: 437) desarrollan en el contexto de la diversidad de “culturas de evaluación”. 
- $\quad$ Capacidad de inferir relaciones entre los recursos de lenguaje audiovisual y los aspectos ideológicos del discurso de ficción.

- $\quad$ En nuestro trabajo ha quedado patente que los participantes han destacado como recursos más relevantes de las tres secuencias la puesta en escena (ambientación de los espacios, vestuario, iluminación...) y la interpretación actoral. Sin embargo, las consideraciones de gusto personal se han focalizado en el guión y los diálogos. Ello permite suponer que los sujetos son competentes en la atribución de significado a los elementos escénicos en su globalidad, pero que dirigen de manera espontánea sus argumentos valorativos hacia los elementos más literarios del discurso audiovisual.

En segundo lugar, destacar la identificación en el testimonio de los sujetos de distinciones entre la concepción personal sobre el amor y su percepción de la representación mediática. La opinión de los participantes sobre la representación del amor en los tres ejemplos visionados obtenida en las entrevistas, es consistente con los comentarios del grupo de discusión. Así, un 90\% de la muestra subraya la crítica a los estereotipos de género en la representación de las relaciones amorosas y un 80\% reclama una mayor complejidad en los guiones y desarrollo de personajes. Los resultados, sobre todo en el grupo de discusión, indican que los participantes se alejan de la idea de un mundo dividido entre "hombres masculinos" y "mujeres femeninas”, en la línea de otras investigaciones precedentes (Medina et al., 2008; Aran, Medina, Rodrigo, 2010). En especial, rechazan la representación de los personajes femeninos y abogan por una mayor complejidad en la construcción de los personajes y las tramas. La presencia creciente en las series de personajes con una opción sexual homosexual se considera todavía estereotipada.

Los resultados también han señalado que cuanto más próxima es la representación a la tipología de amor pasional, más fácil es reconocer en ella la presencia de estereotipos. Tanto en su posicionamiento personal (más manifiesto entre algunos participantes que en otros), como en la interpretación que efectúan sobre la representación ficcional, los sujetos se alejan del “ideario romántico” tradicional, como réplica actualizada del antiguo amor cortés del siglo XII (Courtin, 2004; Markale, 2006). Ello permite suponer que la gran mayoría de los participantes de la investigación parecen rechazar la noción de unas relaciones amorosas basadas en el romanticismo y en los estereotipos de género.

Sin embargo, en el caso del único ejemplo de amor consolidado o consumado (de acuerdo a la clasificación de Sternberg, 1989), la complejidad de la representación no es necesariamente bien recibida: el rechazo de los participantes se dirige a lo que interpretan en clave de incomunicación de la pareja. Se pone de manifiesto la necesidad de reflexionar con más profundidad sobre los procesos de creación y de recepción de modelos amorosos menos convencionales, que parecen tener una lectura y aceptación más 
difícil, en contraste con la demanda explícita de mayor visibilidad de nuevos modelos amorosos en la oferta de ficción. Es posible que el ejemplo escogido haya resultado demasiado confuso, pero nos parece importante enfatizar que la dificultad de comprensión no aparece tanto ante la representación de una relación homosexual como ante una forma de amor menos convencional respecto a la hegemonía del amor pasional y romántico.

En este mismo sentido, en el análisis detallado se observa como algunos sujetos valoran positivamente en la ficción, sobre todo cuando se presenta en un tono de entretenimiento ligero y con pinceladas de humor, la presencia de comportamientos gentiles o caballerosos entre los personajes masculinos y una cierta complacencia hacia el estereotipo de la fragilidad emocional femenina. Es un dato que aparece reflejado claramente en las entrevistas pero que en el grupo de discusión queda desdibujado ante las intervenciones más dominantes que abogan por otro tipo de representaciones menos discriminatorias o convencionales.

Nuestro estudio no permite señalar una relación de causalidad entre la formación en educación mediática de los participantes y una cultura de géneros igualitaria, pero sí pensamos que favorece una explicación de su influencia mutua. En este sentido hemos podido apreciar una interacción dialógica entre conocimientos específicos en lenguaje audiovisual y una lectura contextual coherente con las dimensiones expuestas de la educación mediática. Como se ha referido, tanto los comentarios -en las entrevistas, pero particularmente en los focus group - referidos al contenido de las series mostradas (tipos de personajes, de relaciones amorosas representadas así como el ideario amoroso latente) como las referencias a la estructura narrativa, caracterización de personajes, e incidencia de aspectos formales y estéticos del lenguaje audiovisual, nos permiten finalmente señalar, de manera forzosamente esquemática, la presencia en los participantes de los siguientes elementos relacionados con una formación y educación mediática en relación a la representación de las modalidades amorosas y su significación social:

- Habilidad para conectar las observaciones particulares sobre el estilo y contenido del discurso audiovisual en un contexto social amplio.

- Compromiso crítico con los temas y estrategias del discurso televisivo ficcional. En particular, aparecen como relevantes las cuestiones referidas a la identidad (de clase, de género, sexual) y a la ideología.

- $\quad$ Conocimiento del potencial y de la significación social que tiene la corriente dominante y hegemónica de los media. 
En síntesis, los resultados obtenidos, que surgen a partir del trabajo con un target específicamente formado en educación mediática de un centro de referencia internacional en formación e investigación en educación mediática, desvelan datos optimistas sobre el beneficio de esa interacción dialógica entre conocimientos en lenguaje audiovisual y una educación mediática comprehensiva, pero revelan contrastes entre el análisis crítico de las representaciones amorosas y los posicionamientos personales sobre modelos de amor. El diseño de la investigación no hace posible una extrapolación de los resultados pero sí nos permite señalar la necesidad de complementarlos con nuevas propuestas de investigación.

Finalmente, un mayor conocimiento del lenguaje audiovisual -que es la dimensión en que hemos centrado este artículo-, pero también del conjunto de procedimientos discursivos y de las estrategias empresariales de las industrias culturales ha de servir como oportunidad para pensar, construir (y cómo consumir) nuevos relatos. A nuestro parecer, la educación mediática tiene algo relevante que aportar a la capacitación crítica de los espectadores y en la defensa de una representación de nuevas y más equilibradas relaciones amorosas.

\section{Apoyos}

La investigación que aquí se resume ha sido posible gracias a una beca Postdoctoral de estancias de investigación en el extranjero de la AGAUR (BE 2009), y gracias a la colaboración de los estudiantes del Master y al apoyo del IOE, Institut of Education de la University of London, en particular del profesor David Buckingham.

\section{Referencias bibliográficas}

Ang, I. (1996): Watching Dallas. Soap opera and the melodramatic imagination. Londres: Routledge.

Aran, S.; Medina, P.; Rodrigo, M. (2010): "Management of emotions in american fiction series: when being (and feeling like) woman sales", IJART, volumen 4 (issue 1/2, en prensa).

Aran, S. (2008): Representació mediàtica i percepció social de la violència en la ficció. Estudi de cas: la interpretació dels infants de la violència en la ficció televisiva infantil. Tesis doctoral (URL). Barcelona, 2008. http://www.cac.cat/web/ recerca/estudis/ llistat Consulta: 5 de diciembre 2010

Bazin, A. (1990): ¿Qué es el cine? Madrid: Rialp.

Bordwell, D.; Thompson, K. (1996): La narración en el cine de ficción. Barcelona: Paidós.

Buckingham, D (2003): Media Education. Literacy, learning and contemporary culture. Cambridge: Polity. 
Buckingham, D.; Domaille, K. (2001): Where are we going and how can we get there?: general findings from the UNESCO Youth Media Education Survey 2001. Unesco, 2001. Disponible en línea en: http:/ /www.european-mediaculture.org/fileadmin/ bibliothek/english/buckingham_where/buckingham_where. pdf [Consulta: 30 de junio de 2011]

Butler, J. (1990): Gender Trouble: Feminism and the Subversion of Identity. Londres: Routledge.

Courtin, J. et al. (2004): La historia más bella del amor. Barcelona: Anagrama.

Ferrés, J. (2006): “La competència en comunicació audiovisual: proposta articulada de dimensions i indicadors”. Quaderns del CAC, núm. 25, mayo-agosto 2006, pp.9-17. Disponible en línea en: http://www.cac.cat/web/recerca/quaderns/hemeroteca/ [Consulta: 30 de junio de 2011].

Fòrum d'entitats de persones usuaries de l'audiovisual (2006): "L'educació en comunicació audiovisual: perspectives i propostes d'actuació a Catalunya”. Quaderns del CAC, núm. 25, mayo-agosto 2006, pp.19-27. Disponible en línea en: http://www.cac.cat/web/recerca/quaderns/hemeroteca/ [Consulta: 30 de junio de 2011]

Funge, E. (1998): "Rethinking representation: Media Studies and the posmodern teenager", English and Media Magazine, no 39, pp. 33-36.

Galán, E. (2007): La imagen social de la mujer en las series de ficción. Cáceres: Universidad de Extremadura.

Markale, J. (2006): El amor cortés o la pareja infernal. Palma de Mallorca: José J. de Olañeta.

McRobbie, A. (2004): Post-feminism and Popular Culture. Routledge. Feminist Media Studies Vol. 4, No. 3, 2004.

Medina, P.; Rodrigo, M. (2009): "Análisis de la estructura narrativa del discurso amoroso en la ficción audiovisual. Estudio de caso: "Los Serrano" y "Porca Misèria"”. Zer, pp. 83-101.

Medina, P.; Rodrigo, M.; Aran, S.; Munté, R.-A.; Tharrats, J. (2008): “Els models d'amor en la ficció televisiva seriada. Estudi de cas: "Porca Misèria", Quaderns del CAC, 29, 81-90.

Medina, P.; Aran, S.; Rodrigo, M.; Munté, R.-A.; Tharrats, J. (2007): Violència simbòlica i models amorosos en la ficció televisiva seriada per al consum adolescent i juvenil. Estudi de cas ("Porca Misèria")". Informe de Investigación del Proyecto financiado por el Consell de l'Audiovisual de Catalunya www.cac.cat

Medina, P.; Aran, S.; Rodrigo, M.; Munté, R.-A.; Estrada, A,; Medina, A.; Tharrats, J. (2007b): I tu, de què vas? La perspectiva de gènere en la relació de parella. Projecte formatiu per a la coeducació. Informe de Investigación del Proyecto financiado por el Institut Català de les Dones.

Medina, P.; Rodrigo, M.; Aran, S. et al. (2006): La representación del discurso amoroso en la ficción audiovisual: ¿̨creatividad limitada?. Las encrucijadas de la comunicación: límites y transgresiones. IV Congrés Internacional Comunicació i Realitat, Barcelona Trípodos, Extra 2007, pp. 705-718.

Monereo, C.; Castelló, M. et al. (2009): “Las bases psicoeducativas del proyecto PISA como guía para el cambio en las concepciones y prácticas del profesorado de secundaria”. Infancia y aprendizaje, 32 (3), pp. 421-447. 
Oliva, M. (2006): “Panoràmica de l'educació en comunicació audiovisual”. Quaderns del CAC, núm. 25, mayo-agosto 2006, pp. 29-39. Disponible en línea en: http://www.cac.cat/web/recerca/quaderns/hemeroteca/ [Consulta: 30 de junio de 2011]

Sternberg, R.J. (1989): El triángulo del amor. Intimidad, pasión y compromiso. Barcelona: Paidós.

Sternberg, R. J. (2000): La experiencia del amor. La evolución de la relación amorosa a lo largo del tiempo. Barcelona: Paidós.

Thompson, B. J. (1998): Los media y la modernidad. Una teoría de los medios de comunicación. Barcelona: Paidós.

Williams, R. (1975): The Long Revolution. Londres: Penguin. 